\title{
Contribuições de Viktor Frankl ao sentido da vida e na temporalidade contemporânea
}
Viktor Frankl's contributions to the meaning of life and in the contemporary temporality

Daniel Fortunato Burgese ${ }^{1}$

Daniela Ceron-Litvoc ${ }^{2}$

\section{Resumo}

A partir da metade do século XIX, com o advento sem precedentes de novas tecnologias, o homem passa a vivenciar uma importante alteração da percepção do outro, do tempo e do espaço. A aceleração do tempo promovida por essas novas tecnologias não permite o exercício da afetividade para a consolidação de laços, as relações assumem matizes narcisistas que buscam gratificações imediatas e o outro é entendido como uma continuidade do eu, na busca do prazer. Viktor Emil Frankl (19051997) parte do pressuposto de que a principal fonte motivadora do ser humano é a busca do sentido, algo em função do que se vive. Fenômenos patológicos, tais como depressão, ansiedade e dependências de substâncias, de uma forma geral, não podem ser entendidos e tratados sem o reconhecimento do vazio existencial subjacente a eles. A estrutura psíquica que, frente a novos fenômenos vivenciados, perde a capacidade de temporalizar e expandir sua espacialidade, torna-se patológica. Essa incapacidade pósmoderna de reter o passado, de analisar as informações recebidas e refletir, é uma das responsáveis pelo adoecimento psíquico da sociedade atual. A temporalidade tem papel crucial para o entendimento da resiliência. Estas devem ser as marcas da temporalização saudável do indivíduo, na contemporaneidade.

Palavras-chave: Percepção do tempo; Resiliência psicológica; Fenômenos e processos psicológicos; Espaço pessoal; Análise espaço-temporal 


\begin{abstract}
From the mid-nineteenth century, with the advent of new technologies unprecedented, man begins to experience a significant change in the perception of another time and space. The acceleration time promoted by these new technologies do not allow the exercise of affection for the consolidation of ties, relations assume narcissists hues seeking immediate gratification, the other is understood as a continuity of the self in pursuit of pleasure. Viktor Emil Frankl (1905-1997) assumes that the main motivating source of the human being is the search for meaning, something against which one lives. Pathological phenomena such as depression, anxiety and substance dependencies in general, cannot be understood and processed without the recognition of the underlying them existential vacuum. The psychic structure opposite the new phenomena not restructures, which loses its ability to expand it's temporalize and spatiality becomes pathological. This postmodern inability to retain the past, analyze the information received and reflection are the one responsible for mental illness in society today. The temporality plays a crucial role in understanding the resilience should be the trademarks of temporality in healthy individuals nowadays.
\end{abstract}

Keywords: Perception of time; Psychological resilience; Psychological processes and phenomena; Personal space; Spatiotemporal analysis

\footnotetext{
${ }^{1}$ Instituto de Assistência Médica ao Servidor Público Estadual - IAMSPE - São Paulo (SP), Brasil. E-mail: danielburgese@yahoo.com.br

${ }^{2}$ Faculdade de Ciências Médicas da Santa Casa de São Paulo - FCMSCSP - São Paulo (SP), Brasil.E-mail: daniela@ ceronlitvoc.com
}

Recebido em: 9/5/2015

Aceito em: 17/9/2015 


\section{Introdução}

A partir da metade do século XIX, com o advento sem precedentes de novas tecnologias, o homem passa a vivenciar uma importante alteração da percepção do outro, do tempo e do espaço. A aceleração do tempo promovida por essas novas tecnologias não possibilita o exercício da afetividade para a consolidação de laços, as relações assumem matizes narcisistas que buscam gratificações imediatas e o outro é entendido como uma continuidade do eu, na busca do prazer.

É a aceleração do tempo, novamente, que leva o homem a apresentar a necessidade do imediato, sempre à procura da novidade - não do novo -, na tentativa de preencher um espaço interno que se encontra esvaziado. Esse espaço vazio é chamado por Viktor Emil Frankl, de vácuo existencial. A partir de 1945, descreve a ausência de sentido futuro como fator gerador de sofrimento psíquico.

Objetivamos, com este artigo, associar as ideias do vácuo existencial de Frankl com as modalidades da fenomenologia estrutural, atribuindo alterações na temporalidade e relações interpessoais como forma do adoecer psíquico na cultura contemporânea.

\section{Contexto histórico}

Viktor Emil Frankl (1905-1997) foi um psiquiatra austríaco, fundador da chamada logoterapia, escola psicológica de caráter fenomenológico, existencial e humanista, conhecida, também, como a "Psicoterapia do Sentido da Vida" ou, ainda, a Terceira Escola Vienense em Psicoterapia, depois das escolas de Freud e Adler. O significado de logos atribui-se a sentido e, terapia, ao termo cura. Assim, o termo logoterapia significa a cura através do sentido. Diferente da psicanálise freudiana e da psicologia adleriana, que reduzem o ser humano às dimensões biológica e psíquica, Frankl apresenta o indivíduo em três dimensões: psique - corpo - noos (espiritual).

Descendente de família judaica, ainda em sua juventude, Frankl mostrou-se crítico à ciência reducionista e interessado nas questões especificamente humanas. Aos 16 anos, escreveu uma carta a Freud, que respondeu e o estimulou a continuar escrevendo. Manteve contato com Freud, por meio de cartas, até os 19 anos, quando encaminhou a este um ensaio intitulado "Sobre os movimentos da mímica de afirmação e negação" (Frankl, 1924), que foi prontamente acolhido e enviado ao Jornal 
Internacional de Psicanálise, tendo sido publicado em 1924. Apesar de residirem na mesma cidade, somente em 1925, quando Frankl já era estudante de Medicina, encontrou-se pessoalmente com Freud. O início de sua trajetória profissional, como médico psiquiatra, envolveu a organização de Centros de Aconselhamento Juvenil e de uma ação extraordinária de prevenção ao suicídio. Tratou mais de 900 jovens com ideação suicida e, em 1925, em Viena, não ocorreram suicídios entre jovens, fato que teve importante ressonância no exterior (Oliveira, Gaglietti \& Kujaua, 2011). Como diretor do pavilhão de mulheres suicidas do Hospital Psiquiátrico de Viena, sabotou as ordens nazistas de proceder à eutanásia dos doentes mentais que estavam sob seus cuidados. Tais experiências o impulsionaram ainda mais a ampliar os estudos sobre o sentido da vida e a psicoterapia.

Durante a Segunda Guerra Mundial, foi feito prisioneiro nos campos de concentração nazistas. Inicialmente, em 1943, permaneceu no campo de Therezin República Tcheca e, em 1944, foi enviado a Auschwitz - Polônia. Nessa época, vivenciou o falecimento de sua esposa grávida e de seus pais e irmãos, durante o holocausto. Após ser libertado, em 1945, escreveu o livro "Em busca de sentido - Um psiquiatra nos campos de concentração" (Frankl, 1984), no qual descreve seu cotidiano como escravo e suas vivências aterrorizantes, além de abordar o início de sua teoria sobre o sentido da vida. Retomou o trabalho como psiquiatra/psicoterapeuta em Viena, casou-se novamente, estudou filosofia e intensificou os estudos e publicações sobre a logoterapia.

\section{A busca do sentido}

Frankl parte do pressuposto de que a principal fonte motivadora do ser humano é a busca do sentido, algo em função do que se vive. Segundo sua teoria, o indivíduo que tem um "porque viver" pode suportar "qualquer como", referência ao período que sobreviveu ao holocausto. A teoria de Frankl tem como objetivo o esclarecimento da existência, enfatizando possibilidades de se realizar o sentido da vida. Seus estudos percorrem a dimensão dos fenômenos especificamente humanos, como a liberdade para descobrir o sentido da própria vida, a responsabilidade, o autodistanciamento, a autotranscendência e a capacidade de amar (Roeche, 2005). Afirma que o homem não pode ser concebido como um ser governado por pulsões, como defende Freud, 
reiterando que esta é uma visão determinista, que desconsidera, no homem, sua característica de ser livre e sua habilidade para fazer escolhas conscientes, assumindo responsabilidade pela vida. Segundo ele, esse sentido não pode ser dado arbitrariamente, deve ser buscado conscientemente. Frankl descreve a consciência como a capacidade intuitiva do homem para encontrar o sentido de uma situação, sentido este que, sendo sempre único, não se submete a uma lei geral (Roeche, 2005).

A liberdade, para Frankl, é o que confere a humanidade ao homem, ou seja, a expressão do humano no homem, que é (sendo) mundo. Sua ruptura com as ideias de Adler vem do fato deste acreditar que o homem é movido pela busca do poder (Oliveira et al., 2011; Roeche, 2005). Para Frankl, o que move o homem é a busca por um sentido a realizar na vida e este sentido pode ser encontrado nas situações cotidianas, mesmo nas de sofrimento intenso.

Considera que cada pessoa tem uma vocação própria ou missão específica na vida, uma tarefa concreta, que exige realização. Entretanto, tal tarefa - o sentindo - não é algo estático: o sentido muda de acordo com a pessoa e a situação, uma vez que a existência de cada homem apresenta um caráter único e as situações nas quais está envolvido são irrepetíveis (Frankl, 1986). Entende que o homem não deve perguntar pelo sentido, mas sim perceber-se questionado pela vida, ou seja, conforme as circunstâncias se apresentam, deve responder na forma de uma ação comprometida com um sentido pessoal. Por isso, ressalta a importância da responsabilidade - habilidade para responder.

$\mathrm{Na}$ fenomenologia husserliana, um dos postulados é o entendimento da intencionalidade (Pires, 2012), que significa "dirigir-se para", "visar a alguma coisa". A intencionalidade é o que permite à consciência sair de si mesma, em direção aos fenômenos, acontecendo, então, uma correlação entre os atos de consciência e os objetos constituídos por esses atos. Toda consciência é intencional, por sempre visar algo fora de si e tender para esse algo. Portanto, a consciência é a doadora de sentido e isso aconteceria pelo processo do conhecimento, que não acaba nunca, sendo uma exploração exaustiva do mundo. Husserl afirma que sempre há uma possibilidade da consciência intencional de se dirigir para outro algo para o qual, até então, não se dirigia. Esse processo é descrito por Husserl como modificação de intencionalidade (Pires, 2012). 
Heidegger (1927), em "Ser e tempo", citado por Reis (2005), desenvolve sua analítica do Dasein, como uma interpretação ontológica do sentido de ser. Refere-se ao Dasein como o existir humano, que se dá como um acontecer (sein) que se realiza aí (Da): o próprio existir humano, que constitui o "aí” em que se dá a existência e, neste sentido, o Dasein pode ser pensado não apenas como Ser-aí, mas como o acolhimento daquilo que se dá, enquanto a experiência no mundo. O Dasein, ou a existência, significa que nós não apenas somos, mas percebemos que somos, sem nunca estarmos acabados. Não podemos rodear a nós mesmos, mas, em todos os pontos, estamos abertos para um futuro e temos que conduzir a nossa vida. Estamos entregues a nós mesmos e somos aquilo que nos tornamos. A partir deste conceito, a temporalidade e a historicidade terão importância fundamental na análise heideggeriana.

"Esse sentido último, necessariamente excede e ultrapassa a capacidade intelectual finita do ser humano; (...) o que se requer da pessoa não é aquilo que alguns filósofos existenciais ensinam, ou seja, suportar a falta de sentido da vida; o que se propõe é, antes, suportar a incapacidade de compreender, em termos racionais, o fato de que a vida tem um sentido incondicional. O logos é mais profundo do que a lógica (Frankl, 1986)".

Sobre a temporalidade, Messas (2004) explica que ela "determina a abertura simultânea da consciência e de seus conteúdos, de passado, presente e futuro. A combinação geométrica destas três dimensões faculta à consciência a experiência de fluxo, de uma corrente que a atravessa, partindo do passado, atingindo sua coloração máxima no presente e dirigindo-se, inexoravelmente, a um horizonte sempre inatingível, o futuro". Desta forma, é através da associação do conceito da temporalidade, com seu funcionamento adequado, que a intencionalidade irá exercer seu papel de forma completa, projetando os fenômenos do presente para uma determinação do futuro. Sendo o ser humano uma criatura responsável e que precisa realizar o sentido potencial de sua vida, a decisão por responder e dar significado às situações da própria vida constitui a essência da existência humana, funcionando como um gerador agente da intencionalidade.

O autodistanciamento citado por Frankl (2013) e Roeche (2005) diz respeito à "capacidade do homem de distanciar-se de si próprio". O homem se coloca acima de uma situação, para dominá-la. Ocorre, também, pela autocompreensão, ou seja, à 
medida que a pessoa se compreende, torna-se capaz de distanciar-se de si mesma. Como exemplo, pode ser citado que, diante de atos impulsivos agressivos, o indivíduo pode se posicionar e escolher o que fazer, para depois agir. O conceito de autodistanciamento frankliano pode ser associado ao conceito de espacialidade da visão fenômenoestrutural. Para Messas (2004), a categoria da espacialidade permite "a determinação de fronteiras de um eu, núcleo a partir do qual, este, por assim dizer, troca informações com as diversas modalidades do não-eu, ou do ambiente. Ambiente composto, seja pelas influências da cultura num extremo, até a presença vivenciada do corpo biológico, no outro extremo. A fronteira do eu espacializado determina, assim, a vivência de intimidade com a realidade, daquilo que nos pertence como identidade e patrimônio básico e daquilo que nos atinge como exterioridade, como algo distinto de nós mesmos".

Minkowski (1973) descreve os conceitos de espaço claro e espaço escuro para a compreensão da espacialidade vivida. De acordo com seu conceito, o espaço claro é o espaço das evidências, onde os objetos aparecem e são confirmados pela coletividade e onde podemos ver os fenômenos do mundo, mantendo um distanciamento entre nós e eles. Esse distanciamento é chamado de distância vivida, sendo um espaço livre, no qual se pode exercer a modalidade de expansão ou retração. $O$ espaço escuro diz respeito a um lugar de excessiva intimidade, onde os fenômenos aparecem sem contorno ou nitidez. É a "mundanização do si mesmo, ou seja, da retirada progressiva de sua liberdade e de sua dominação pela necessidade ou pelos acontecimentos".

A respeito do espaço escuro, Binswanger (2009) descreve: “O mundo torna-se, então, o poder que consome as suas forças - e de tal forma que eles se mundanizam mais e mais, ou seja, de pessoas independentes, amorosas e livres eles se transformam em criaturas amarradas ao mundo, que vivem do precisar se comparar, não livres, castigadas pelo medo, tornam-se um joguete de um esboço de mundo - do mundo como perigo". O espaço psíquico é onde a vida pode desenvolver sua amplitude e oposição em relação ao interno e externo. Os elementos sensoriais, os representativos e as significações aparecem na estrutura psíquica em hierarquias espaciais distintas, em um movimento centrípeto, em relação ao eu.

Sonenreich (1999) refere-se ao campo vivencial como espaço no qual se desenrola a atividade global da pessoa, a síntese das informações provenientes do corpo, 
do ambiente, a interpessoalidade, com significados dados pela memória das experiências passadas, pelos valores e projetos, com ressonância afetiva e sugestões de resposta. Quando se rompe a experiência espacial, rompe-se a capacidade de diferenciação do movimento centrípeto de proximidade do eu, sem proteção pelo distanciamento. A consciência torna-se apta a ser invadida e os espaços de intimidade e restritos à individualidade (espaços escuros) são invadidos e corrompidos pelo espaço claro, das influências externas. O espaço, como possibilidade de autonomia para a expansão do psiquismo, é perdido.

O movimento psíquico de aproximação ou retração dos fenômenos vivenciados, através de um mecanismo de elasticidade, proporciona uma relação com o espaço vivenciado. O processo de saúde dependerá da justa proporção entre a espacialidade e temporalidade. Quando existem desproporções entre estes eixos, o homem não poderá se realizar de forma autêntica.

“Ao declarar que o ser humano é uma criatura responsável e precisa realizar o sentido potencial de sua vida, quero salientar que o verdadeiro sentido da vida deve ser descoberto no mundo e não dentro da pessoa humana ou de sua psique, como se fosse um sistema fechado. Chamei essa característica constitutiva de "a autotranscendência da existência humana". Ela denota o fato de que o ser humano sempre aponta e se dirige para algo ou alguém diferente de si mesmo - seja um sentido a realizar ou outro ser humano a encontrar. Quanto mais a pessoa esquece-se de si mesma - dedicando-se a servir uma causa ou a amar outra pessoa -, mais humana será e mais se realizará (Frankl, 2013)".

A autotranscendência (Frankl, 2013; Roeche, 2005) também faz parte da essência humana - o humano é aberto ao mundo, coloca-se em relação, volta para algo ou alguém diferente de si. A autotranscendência se daria por meio da superação de uma existência egoísta; mostra que o humano não se fecha em condicionamentos, mas transcende os condicionamentos psicofísicos, conferindo a si a capacidade de amar. É na experiência da sociabilidade que o homem pode desvelar o sentido que a alteridade confere à sua vida.

As propostas oferecidas por Frankl a respeito da autotranscendência vão ao encontro das descrições de Binswanger (citado por Giovanetti, 2012 e Pereira, 2001) sobre um conjunto de formas que constituem as maneiras através das quais se articula o 
ser-no-mundo. A primeira modalidade seria a forma dual, que possui duas expressões: o amor e a amizade. Essa unidade na dualidade é possível porque o princípio organizador que rege a relação entre um e outro é o encontro e estaria baseado no ser-em-relação-dereciprocidade. A segunda modalidade é a plural, que seria o encontro do ser humano em que duas ou mais pessoas estão em oposição à dualidade e podem articular em duas direções: primeiro, a relação do ser humano com qualquer coisa (mundo circundante) e segundo, a relação humana com outros humanos (mundo social). A singularidade é o terceiro modo humano de articulação e revela o modo em que o Dasein está em relação consigo mesmo.

Messas (2004) descreve o processo de interpessoalidade na fenomenologia estrutural como uma categoria que permite o movimento psíquico, pois "situa-se nas fontes originárias dele, atuando como um catalisador continuado e vigoroso (...); a interpessoalidade é o que dá a garantia da progressão e diferenciação do individual, sua primazia sobre o geral e coletivo; o individual só se gesta no interpessoal" (p. 155). Essa categoria diz respeito à inserção do ser no mundo, sua capacidade de se aprimorar e se relacionar com o coletivo e o espaço.

As formas de relacionamentos humanos descritos por Binswanger 2001, Messas 2004 e Frankl 1986 capturam a base humana nas conexões com o outro. A habilidade humana na retenção temporal do passado, a responsabilização pelas atitudes do presente e a intencionalidade de planejamento do futuro seriam os possíveis meios conscientes humanos para o surgimento da busca do sentido. A liberdade ofertada por Frankl para uma definição do sentido da vida estaria correlacionada com a capacidade de temporalização futura.

A construção de sentido e a combinação entre sentidos e valores, enquanto constituição da pessoa em ser-responsável, não são apenas um desempenho do racional ao razoável, aos conteúdos objetivos e inteligíveis, mas no lidar com os instintos e com o inconsciente humano: um ser humano é um ser respondente quando questiona moralmente o que o afeta, prorrompe sua existência permanentemente - o perceptível no tempo em que se percebe como existente entre os exóticos e os outros. O sentido da existência humana parte da consciência, especialmente da consciência moral, que é perceptível na condição de responsabilidade perante a essência da existência (Frankl, 1989; Husserl, 2001; Mota, 2013). 


\section{Conceito de protensão}

Alguns termos técnicos foram introduzidos na fenomenologia para descrever a experiência imediata do tempo. O termo presente vivo significa a completa experiência imediata de temporalidade que temos em algum instante. O presente vivo, como o todo, é composto de três momentos: impressão primordial, retenção e protensão. A retenção, como o próprio nome sugere, aponta para o passado, retém algo. Retém o presente que passou, retém o presente vivo decorrido, a experiência de temporalidade decorrida. A protensão, a contraparte do futuro dirigido da retenção, abre a exata dimensão do futuro (Sokolowski, 2012).

Husserl, citado por Thomé (2008), entende que o elemento de futuro não é gerado através de uma nova reprodução de imagens oriundas das impressões originárias, mas sim, uma mera modificação projetiva das lembranças (primárias ou secundárias). Possuímos uma única protensão, sem conteúdo próprio, que afeta os objetos temporais e os direciona no sentido das realizações possíveis, gerando, assim, o sentido de futuro. $\mathrm{Na}$ retenção, os acontecimentos cotidianos são retidos na forma de passado e, na protensão, o existente humano antecipa os acontecimentos. Contudo, esta antecipação é sempre feita a partir do momento presente. Assim, o passado é retido como passado, no presente, e o futuro é antecipado como futuro, também a partir do presente. Poderíamos dizer que o presente é uma síntese do que é retido e do que é antecipado. Conforme o antecipado passa, é retido como passado. Portanto, é através do tempo que se dá a unificação das vivências que o eu tem do mundo e é a partir do tempo que se constitui a subjetividade do eu transcendental. Em cada presente há uma retenção do que veio antes e uma protensão do que virá (Husserl, citado por Thomé, 2008).

A descrição da protensão revela que o futuro pode ser projetado, porém, isso não quer dizer que se possa realizar uma descrição integral do que será, mas pode-se organizar a expectativa futura e descrever a sua estrutura fundamental, sem propriamente doar o futuro.

\section{O vácuo existencial}

O vácuo existencial constitui um fenômeno crescente, em franca propagação, tendo como principais manifestações o tédio e a apatia e torna-se um desafio tanto para a educação, quanto para a psicoterapia (Frankl, 2013; Lipovetsky, 2005). Refere-se à 
angústia da pessoa que não tem claro o sentido da própria existência, vivenciando uma vida sem sentido futuro.

A etiologia do vácuo existencial, para Frankl, é uma consequência de diversos fatores influenciáveis ao ser humano. Primeiramente, diferentemente do que acontece com os animais, nenhum instinto ou pulsão diz ao homem o que ele deve fazer. Em segundo lugar, contrariamente ao que ocorria em gerações passadas, na atualidade, as convenções, tradições e valores morais sofrem uma tendência de não mais serem orientadores da moral ao homem contemporâneo, de tal modo que pode suceder uma abolição da vontade pessoal. Nesse modo de funcionamento, ocorre um fenômeno: o homem faz o que os outros fazem, ou faz o que os outros querem que ele faça, se tornando vítima, ora do conformismo, ora do totalitarismo (Frankl, 2013).

Fenômenos patológicos, tais como depressão, ansiedade e dependências de substâncias de uma forma geral, além de causas externas, estruturas genética e psíquica como fatores predisponentes, não podem ser entendidos $\mathrm{e}$ tratados sem $\mathrm{o}$ reconhecimento do vazio existencial subjacente a eles.

A respeito dos valores de atitude, Frankl enfatiza a importância de que o ser humano posicione-se de forma a encontrar sentido nas dificuldades e apresenta o que chama de tríade trágica, composta por sofrimento, culpa e morte (Frankl, 2013). Propõe que o indivíduo adote uma postura de otimismo trágico, ou seja, otimismo diante das dificuldades, de modo que possa transformar o sofrimento em uma oportunidade para crescimento pessoal, assim como encontrar, no sentimento de culpa, motivos para mudar a si mesmo para melhor e, por fim, fazer da finitude da existência um incentivo para a realização de ações responsáveis.

Jaspers (1987) propõe que, frente a diferentes possibilidades de reação a um fenômeno, as relações de compreensibilidade são possíveis de serem analisadas somente de forma individual, ou seja, afirma que frente a uma nova experiência vivenciada, tanto a história biográfica do indivíduo, quanto a sua estrutura psíquica, serão determinantes para o modo de reagir. . Ceron-Litvoc e Tamelini (2011) descrevem que a "biografia é o todo existencial do indivíduo situado em um fluxo temporal, em que os eventos se ordenam de forma qualitativa. Dessa forma, a associação da sucessão de eventos em uma história biográfica com as características constitucionais daquele que recebe os eventos promoverá o desenvolvimento de uma personalidade". 
$\mathrm{Na}$ estrutura psíquica saudável, frente a novos eventos vivenciados, com experiências de alterações na espacialidade e na temporalidade, ocorrerá uma reestruturação dessas estruturas, uma adaptação, com aumento da espacialidade como forma de possibilitar novas experiências, ou seja, a expansão da capacidade do campo vivencial relaciona-se com a capacidade de abranger temas, assuntos e relações. A temporalidade saudável será aquela capaz de manter o fluxo de movimento linear da temporalidade, onde o presente promove as bases para a construção de um futuro que pressupões novidades, ancorado pelas experiências do passado, que caracterizam o indivíduo.

A estrutura psíquica que, frente a novos fenômenos, perde a capacidade de temporalizar e expandir sua espacialidade, torna-se patológica. Temporalidade funcional e espacialidade fixa não determinarão uma estrutura sadia, assim como temporalidade não linear e espacialidade expandida.

\section{Temporalidade na contemporaneidade}

A contemporaneidade experimenta uma tendência ao declínio e afrouxamento de valores universais de moralidade, ética e altruísmo. Em uma sociedade que se ambienta na permissividade e no polimorfismo, onde os prazeres imediatos são aceitos como um modo saudável de vivenciar o espaço, o tempo e os contatos interpessoais, como lançarse em um modo de existência salutar?

O filósofo francês Gilles Lipovetsky (2005) afirma que, atualmente, nas sociedades contemporâneas, o interesse por temas públicos é variável, tornou-se à-lacarte. Os cidadãos podem, eventualmente, mobilizar-se por uma questão ou outra e, logo em seguida, deixarem de manifestar interesse. A sociedade não conhece a procedência, codificações definitivas, centragem, conhece apenas estímulos e opções equivalentes, em cadeia. A partir daí, resulta a indiferença pós-moderna, indiferença por excesso e não por falta, por uma hipersolicitação e não por privação.

Assim que registrado um acontecimento ele é imediatamente esquecido, expulso por outros registros que ocorrem posteriormente, quase que de forma instantânea; cada vez mais informações e sempre com uma velocidade maior e mais intensa. Essa incapacidade pós-moderna de reter o passado, analisar as informações recebidas e refletir, aprender com o fato e estimular esse aprendizado para o futuro é um dos fatores 
responsáveis pelo adoecimento psíquico da sociedade atual. Há uma plena incapacidade na temporalização nos registros de retenção e protensão. A alteração básica na estrutura psíquica da temporalidade, com diminuição da amplitude, pode ter sua contribuição por uma cascata de eventos que levam ao desfecho do vazio existencial.

Ainda de acordo com Lipovetsky (2005), viver o presente, nada mais do que o presente, não mais em função do passado e do futuro, é a "perda do sentido da continuidade histórica", essa erosão do sentimento de pertencer a uma sucessão de gerações enraizadas no passado e se prolongando para o futuro, que caracteriza a sociedade narcisista. Atualmente, vivemos para nós mesmos, sem nos preocuparmos com as nossas tradições e com a nossa posterioridade: o abandono total do sentido histórico, da mesma forma que os valores e as instituições sociais.

O momento moderno revela o processo da indiferença pura no qual todos os gostos e comportamentos podem coabitar sem se excluírem, em que tudo pode ser escolhido à vontade. Como em um modo infantilizado de funcionamento, quando uma criança responde que deseja ter duas ou três profissões que não se relacionam, o homem contemporâneo tem a liberdade para tudo escolher, sem se responsabilizar, não se aprofundando em suas escolhas. Torna-se superficial, tudo é atingível, tudo pode ser alvo do seu desejo, mas não percorre a trajetória necessária para esse alcance.

O que emana do trabalho e do esforço é deixado de lado, torna-se penoso e, o que é penoso, tende a não ser realizado. O destino é colocado quase que ao acaso, o homem não se enxerga como ser responsável pelo resultado final de suas escolhas. Em um ambiente que valoriza o prazer imediato, com ausência de esforço pessoal, a individualidade de ação é o que resulta. A temporalidade é imediatista, com escolhas fáceis e rápidas. Empenhar-se para obter algo em longo prazo, ou ceder seus desejos aos desejos alheios, é um sacrifício quase que desumano.

O impacto na estrutura psíquica dessa nova mentalidade determinada na pósmodernidade já pode ter início com o comportamento conferido por pais/cuidadores aos seus filhos. Cada vez mais frequentemente observamos pais fornecendo aos filhos tablets e jogos eletrônicos, numa atitude de condicionamento para um comportamento social considerado adequado, ou seja, o condicionamento moderno para diminuir a poluição sonora infantil, já que o que é aceito socialmente é a quietude no universo particular. Essa atitude dos pais e cuidadores funcionaria como uma terceirização da 
educação, cuidados e atenção com as crianças. Isso pode atuar como o fator determinante à criança para uma nova forma de se relacionar com o mundo, estabelecendo uma perda da relevância devida nas relações interpessoais, nas quais a hierarquia e a autoridade parental são substituídas por uma espécie de silenciador eletrônico. Essa forma de atuação, em estruturas psíquicas predispostas, pode agir como um gatilho para um novo modo de se relacionarem com o mundo, sendo um gerador do estímulo de isolamento e recolhimento dentro de si mesmas, sem as colocarem de forma efetiva e saudável no universo ao seu redor.

Já no ambiente escolar, essas estruturas psíquicas marcadas pela temporalidade diminuída pela amplitude, ocasionada pelo excesso de experiências sedutoras da atualidade e pela dificuldade de atuação saudável nas relações interpessoais, experimentam os fracassos no desempenho disciplinar, nos estudos, além de frustrações sociais. O prestígio e a autoridade dos professores desaparecem quase que completamente, em um ambiente marcado pela inexistência da hierarquia estabelecida nas relações, onde todos são considerados ocupando a mesma posição social. A palavra mestre, entendida como aquele que detém o conhecimento e serve de guia para os imaturos, deixa de ocupar o lugar de evidência e torna-se banal, em uma condição de igualdade com a palavra da mídia e experiências imediatas. Para o estabelecimento de uma hierarquia, como por exemplo, na figura do mestre, é necessária uma propagação temporal mais longa na consciência, do que a atual sociedade propicia. Essas sequências de eventos transformam o ensino em maquinário marcado pela apatia, composto por uma atenção dispersa e de descrença, em relação ao saber.

Depois dos 25 ou 30 anos, são as perturbações do tipo narcisístico que constituem a maior parte dos transtornos mentais tratados pelos terapeutas, enquanto as neuroses clássicas do século XIX, como histeria, fobia e obsessões, sobre as quais a psicanálise tomou corpo, não representam mais a forma predominante dos sintomas (Frankl, 2013; Lipovetsky, 2005). Os sintomas se manifestam por meio de um mal-estar difuso e invasor, de um sentimento de vazio interior e de absurdo da vida, de uma incapacidade de sentir as coisas e as pessoas. Os pacientes não sofrem mais de sintomas fixos, mas sim de perturbações vagas e difusas e dificuldade na formação de vínculos interpessoais efetivos. 
Após décadas vivenciando um ambiente social onde o processo da indiferença pura, no qual todos os gostos e todos os comportamentos podem coabitar sem se excluírem, tudo pode ser escolhido à vontade, em um tempo desvitalizado, sem referência estável e sem maior coordenação (Lipovetsky, 2005). Os valores perdem suas referências, somos informados o tempo inteiro com novos costumes e sobre como devemos agir e pensar (moda, artes, música, esportes e política, etc.). Os conceitos de retenção e protensão da temporalidade são liquefeitos, tornam-se fugazes. Aprendemos a viver o mundo e a relação com o outro de uma maneira leviana e superficial. Novas informações chegarão. Nada é tão perturbador quanto a próxima notícia que irá acontecer, nada é retido e nada é deixado na consciência para a protensão. A patologia mental obedece à lei do tempo, cuja tendência é a completa redução das rigidezes e as liquefações de referências estáveis.

Sem exercer a plena capacidade de retenção e protensão, em consequência da não assimilação do passado e do não empenho na construção do futuro, o amanhã se torna um palco ameaçador e incerto, restando debruçar-se sobre o presente e permanecer em uma juventude sem fim. Esse modo de ação gera um ideal de justiça pessoal invertido, onde o homem vivencia um sentimento de ser merecedor de uma condição futura marcada pelo primor e brilhantismo, mas sem nunca ter o esmero e a responsabilidade para esse acontecimento. $\mathrm{O}$ outro se torna responsável pela edificação do seu futuro pessoal, ocorrendo uma total inversão de preceitos.

A sensação de vazio da contemporaneidade, do ponto de vista fenomenológico, pode ser descrita como uma incapacidade de vivenciar a temporalidade. Torna-se o humano presentificado em um tempo com amplitude diminuída, que não permite ter uma continuidade sadia. Como nada é retido, perdem-se os valores morais nas relações interpessoais, há um rompimento na temporalidade entre as relações da existência descritas por Binswanger (citado por Giovanetti, 2012), ou seja, o homem torna-se incapaz de articular, de forma saudável, entre as modalidades do ser-em-direção-de-simesmo e das conexões com o ser-no-mundo.

De uma forma análoga, o homem, na atualidade, vivencia sua relação com o mundo e a relação com seus pares como o maníaco, não na aceleração psíquica apresentada por este, mas em relação à temporalidade. Está presentificado, ancorado no momento atual, no aqui e agora. Perdeu a capacidade de reter o passado e projetar o 
futuro. A temporalização do presente é imediata, não é retida, torna-se fugaz e a tentativa de prever ou enxergar o futuro se esvai completamente, não existe. O futuro é um lugar distante, onde não existe nenhuma relação com o presente ou com o passado. O homem é determinado pelo externo, pelas informações que o circundam, perdeu a capacidade de se tornar sujeito, de subjetivar. Talvez, por essa justificativa, as "patologias do vazio", como os transtornos de personalidade borderline, a dependência do uso de substâncias psicoativas, os transtornos dos impulsos, como compras excessivas e sexo, estão se tornando cada vez mais frequentes na clínica psiquiátrica. São patologias que podem, também, ser enquadradas em uma temporalidade com diminuição da amplitude, sem retenção e protensão.

Não estamos no vazio puro, mas sim perdidos entre tantas referências na contemporaneidade. A todo instante somos invadidos por informações rápidas, complementares e superficiais, como, por exemplo, a agilidade de receber e obter informações via mensagens instantâneas, acesso à internet, em celulares e tablets. Essas informações nos passam a sensação de sermos repletos, com conteúdo necessário para a vivência, porém, essa é uma sensação mascarada, somos invadidos pelo impessoal, pelo que não completa e é prófugo.

\section{$O$ conceito de resiliência}

Em psicoterapia, o estudo do fenômeno da resiliência é relativamente recente (Silveira \& Mahfoud, 2008). Resiliência é um termo próprio da física e se refere à capacidade dos corpos responderem a choques, golpes ou pressão, comprovando a resistência do material, frente ao impacto. Mede a capacidade do corpo para recuperarse, retroceder e reassumir sua forma e tamanho originais, depois de ter sido comprimido, apertado, dobrado ou esticado.

É descrita como a capacidade do ser humano em responder, com caráter prático, às demandas da vida cotidiana, apesar das adversidades que enfrenta ao longo de seu desenvolvimento. É referida por processos que explicam a "superação" de crises e adversidades em indivíduos, grupos e organizações (Frankl, 1989). A resiliência manifesta-se como um fenômeno comum e presente no desenvolvimento de qualquer ser humano. Silveira e Mahfoud (2008), sintetizam o conceito, definindo o termo como a capacidade de transformar uma situação de dor em possibilidade de crescimento, ou 
"capacidade humana para enfrentar, sobrepor-se e ser fortalecido ou transformado por experiências de adversidade".

$\mathrm{Na}$ teoria proposta por Viktor Frankl, todo ser humano tem um potencial para resistir ao sofrimento e conta com fortalezas em seu interior, que lhe permitem superar situações adversas, à medida que elas vão se apresentando ao longo da vivência.

Diante das adversidades impostas, haverá o homem que dotar a vida de sentido, nas situações mais difíceis, nas quais o que importa é dar testemunho da melhor e exclusiva potencialidade humana: transformar a tragédia, a doença, a deficiência ou o fracasso em um triunfo pessoal, em um sucesso humano. A vida cobra mais sentido quanto mais difícil se faz. Se a vida tem sentido, também o sofrimento, necessariamente, o terá. Aflição e morte fazem parte da vida como um todo (Silveira \& Mahfoud, 2008).

Para um exercício de funcionalidade sobre as três formas propostas por Frankl (1978) sobre a descoberta do sentido de vida, é necessária uma estrutura psíquica marcada por uma temporalidade sadia. O sentido do sofrimento só pode ser encontrado e dado por cada pessoa, particularmente, e dependerá da atitude da pessoa. Se realizar os valores que lhe são oferecidos pela situação sofrida e pelo seu pesado destino, ela encontrará dignidade em seu sofrimento (Frankl, 1978). O homem sempre estará exposto a estímulos e determinações ambientais de diversas ordens, mas essa liberdade refere-se à maneira criativa e própria de cada indivíduo, expressa no momento em que responde a eles.

Minkowski (2000), em seu artigo intitulado "Breve reflexões a respeito do sofrimento", afirma que "o sofrimento é parte integrante da existência humana e sofrer faz sofrer. Não se escapa dele de forma alguma e é necessário percorrer esse caminho, quer se queira ou não". Relata que o sofrimento está em nós e nele tomamos contato com nós mesmos e com a nossa existência. O homem, em sua essência irá sempre conhecer o sofrimento. Minkowiski (2000) descreve o sofrer como "todo fenômeno fundamental, é colocado na perspectiva sobre o vivido, destaca-se do que está em movimento e do que é vivo. Penando, do verbo penar, nós avançamos a vida, somos feitos para isso e isso dá a esse avanço seu verdadeiro sentido. A possibilidade de avançar assim, a brecha que ele contém em direção ao futuro - nunca se tem certeza de 
ser bem-sucedido - revalorizam de fato esse penar, apenas no seu caráter prático, e talvez, até mesmo, em razão dele, um fator constitutivo da existência".

Tornar-se resiliente é manifestar o que está latente. A manifestação, o despertar dessa possibilidade poderá variar de um indivíduo para o outro, conforme o entorno e as situações de vida favoreçam, ou não. Uma intervenção nesse sentido deveria tratar de mobilizar a existência espiritual, no sentido de uma responsabilidade livre, contrapondo-se aos condicionamentos da facticidade psicofísica que as pessoas tendem a aceitar como destino (Frankl, 2013). Precisamente, frente a esta facticidade, deve ser despertada a consciência da liberdade, aquela liberdade e responsabilidade que constituem o ser humano, propriamente dito. Tornar-se resiliente é vitalizar a temporalidade em sua amplitude, encontrando, assim, o que está latente. A remodelação dessa estrutura psíquica não saudável, deformada por uma temporalidade marcada pela diminuição de amplitude e com frouxidão nas associações de comunicação interpessoal, pode ser configurada por meio do estímulo propiciado pelo contato interpessoal da psicoterapia.

\section{Considerações finais}

O que deve ser posto, de antemão, na busca, não é o conceito de buscar a felicidade, o sucesso e a realização pessoal. No sentido de essência da existência, devese buscar o que é a decorrência de algo, não se deve buscar o êxito, pois tal busca faz recair no que Frankl (2013) chama de hiperintenção, como princípio de causa, frigidez diante da tensão que se tem, mediante o fim que se busca. A dor tem um sentido potencial de vida quando se tem valores objetivos envolvidos para além de qualquer dor, como realizações ou ações a serem concretizadas.

Sendo o ser humano dotado de uma capacidade de perceber-se, quando inicia o ato de pensar criticamente e lança seu olhar ao mundo pela forma como vive e reflete, nasce existencialmente, expressa sua perplexidade diante de suas vivências, respondendo aos questionamentos sobre quem é, o que faz aqui, o que é viver, qual o motivo de seu bem-estar, por que sofre, por que sua vida é tão desafiadora, por que existem injustiças e sofrimentos. Percebe-se como ser-no-mundo, um ser que faz parte de uma existência maior que sua corporeidade. 
O ser humano tem a particularidade de decidir o que vai se tornar e a questão do sentido da vida torna-se essencial. Entende que é necessário descobrir o sentido da vida, um sentido que o motive e o faça caminhar com responsabilidade, perante o passado inevitável e pelo futuro decisivo.

Viktor Frankl descreve, em toda a sua obra, as condições necessárias para essas descobertas. Mostra que isso é viável, que é possível estabelecer uma trajetória de vida, fazer escolhas saudáveis no presente para um maior aproveitamento futuro, aprendendo e retendo com as vivências do passado e aprimorando um sentido de futuro.

Descobrir-se a si mesmo, como o aí do ser, como ser-no-mundo é, ao mesmo tempo, uma experiência libertadora e uma responsabilidade. Uma responsabilidade porque nos descobrimos como o fundamento sem um fundo objetivo, como abertura sem referências inquestionáveis, como transcendência e historicidade, acontecendo no horizonte da finitude e da concretude. Lutamos, constantemente, contra a morte, sufocamos a consciência e a culpa e somos amparados pela impessoalidade do "a gente", numa familiaridade que nos causa certa tranquilidade e sossego (Seibt, 2012).

A estrutura saudável deve ser capaz de proporcionar sentido às vivências, mesmo nas adversidades. Para isso, a resiliência torna-se a marca fundamental do homem para projetar o seu destino. A temporalidade tem papel crucial para o entendimento da resiliência, a aceitação do presente como resultado da retenção do passado e o presente como uma forma de projeção ao futuro, marcas da temporalização saudável do indivíduo, na contemporaneidade.

Biswanger (2001), citado por Giovanetti (2012) e Pereira (2001), descreve que a psicoterapia, em sua forma e função mais próprias, ou seja, que suscitam e educam a comunicação, mostra o médico sempre em um papel propriamente espiritual de mediador entre o doente e o mundo, o que, corretamente compreendido, nunca pode querer dizer algo que não seja uma mediação entre o doente como não si mesmo e o doente como si mesmo. O caminho para si mesmo sempre passa pelo mundo, assim como o caminho do mundo para o mundo passa por si mesmo. Qualquer psicoterapia bem compreendida é o entendimento humano de sua própria biografia, a concordância do homem consigo mesmo e com o mundo. É a transformação da hostilidade em relação a si mesmo, em beneficência consigo mesmo e, portanto, com o mundo. 
A partir de uma temporalidade com amplitude de funcionamento adequada, os processos de relação consigo e com seus pares, terão a sustentação necessária para tornarem-se viáveis e sadios. 


\section{Referências}

Binswanger, L. (2001). Sobre a psicoterapia. Revista Latinoamericana de Psicopatologia Fundamental. IV(1), 143-166.

Binswanger, L. (2009). O caso Jurg Zund. São Paulo, SP: Escuta.

Ceron-Litvoc, D., \& Tamelini, M. (2011). Transtorno do estresse pós-traumático na visão Fenomenológica. In R. Payá (Org). Intercâmbio das Psicoterapias (p. 149154). São Paulo, SP: Roca.

Frankl, V. (2013). A vontade de sentido: fundamentos e aplicações da logoterapia. São Paulo, SP: Paulus.

Frankl, V. E. (1924). Zur mimischen Bejahung und Verneinung (Affirmation and Denial). Internationale Zeitschrift fur Psychoanalyse, 10, 437-438.

Frankl, V. E. (1978). Fundamentos antropológicos da psicoterapia. Rio de Janeiro, RJ: Zahar.

Frankl, V. E. (1986). Psicoterapia e sentido da vida. (A. de Castro, Trad.). São Paulo, SP: Quadrante. (Originalmente publicado em 1946).

Frankl, V. E. (1989). Um sentido para a vida. (V. Lapenta, Trad.). Aparecida, SP: Santuário. (Originalmente publicado em 1978).

Frankl, V. (1984). Em busca de sentido: um psiquiatra nos campos de concentração. Recuperado de http://gropius.awardspace.com/ebooks/frankl.pdf

Giovanetti, J. P. (2012). O existir humano na obra de Ludwig Binswanger. Síntese Nova Fase, 50,87-99.

Husserl, E. (2001). Meditações Cartesianas - introdução à fenomenologia. (Tradução de Frank de Oliveira). São Paulo, SP: Mandras.

Jaspers, K. (1987). Psicopatologia geral (2a ed.). Rio de Janeiro, RJ: Atheneu. (Originalmente publicado em 1913).

Lipovetsky, G. (2005). A era do vazio: ensaios sobre o individualismo contemporâneo. São Paulo, SP: Manole.

Messas, G. P. (2004). Psicopatologia e transformação: em esboço fenômeno-estrutural. São Paulo, SP: Casa do Psicólogo.

Minkowiski, E. (2000). Breves reflexões a respeito do sofrimento. Revista Latinoamericana de Psicopatologia Fundamental. III(4), 156-164.

Minkowski, E. (1973). El tempo vivido. México, DF: Fondo de Cultura Económica. 
Mota, G. R. (2013). Sobre a consciência moral e a alteridade no pensamento de Viktor Frankl e Emmanuel Levinas (Dissertação de mestrado). Pontifícia Universidade Católica, Rio Grande do Sul.

Pereira, M. E. C. (2001). Sobre os fundamentos da psicoterapia de base analíticoexistencial, segundo Ludwig Binswanger. Revista Latinoamericana de Psicopatologia Fundamental. IV, 137-142.

Pires, J. J. (2012). Considerações sobre o conceito de intencionalidade em Edmund Husserl. Kínesis, $\quad$ IV(7), 286-302. Recuperado de http://www.marilia.unesp.br/Home/RevistasEletronicas/Kinesis/jesuinopires286302.pdf

Reis, J. (2005). O tempo em Heidegger. Revista Filosófica de Coimbra, 28, 369-414.

Roeche, M. V. (2005). Revendo ideias de Viktor Frankl no centenário de seu nascimento. Psico Porto Alegre, 36(3), 311-314.

Seibt, C. L. (2012). ccccTemas em Psicologia, 20(1), 203-212.

Silveira, D. R., Mahfoud, M. (2008). Contribuições de Viktor Emil Frankl ao conceito de resiliência. Estudos de Psicologia (Campinas), 25(4), 567-576.

Oliveira, L. R. F., Gaglietti, M. J., \& Kujaua, I. (2011). Resiliência a partir da teoria de Viktor Frankl: uma proposta psicoterápica (trabalho de conclusão de curso). Faculdade Meridional, Passo Fundo.

Sokolowski, R. (2012). Introdução à Fenomenologia. São Paulo, SP: Loyola.

Sonenreich, C., Estevão, G., \& Altenfelder, M. (1999). Psiquiatria: notas, propostas, comentários. São Paulo, SP: Lemos-Editorial.

Thomé, S. C. (2008). Subjetividade e tempo na Fenomenologia Husserliana (Dissertação de mestrado). Universidade Federal do Paraná, Curitiba. 